\title{
Increased retention of functional fusions to toxic genes in new two-hybrid libraries of the $E$. coli strain MG I 655 and B. subtilis strain I 68 genomes, prepared without passaging through $E$. coli Steven A Haney*, David Keeney, Lei Chen, Soraya Moghazeh, Steve Projan and Beth Rasmussen
}

Address: Department of Infectious Disease, Wyeth Research, 401 N. Middletown Rd., Pearl River, NY 10965, USA

Email: Steven A Haney* - shaney@wyeth.com; David Keeney - TKBeans@AOL.com; Lei Chen - chenl2@wyeth.com; Soraya Moghazeh - smoghazeh@parpharm.com; Steve Projan - projans@wyeth.com; Beth Rasmussen - rasmusb@wyeth.com

* Corresponding author

Published: 10 September 2003

BMC Genomics 2003, 4:36

This article is available from: http://www.biomedcentral.com/I47I-2/64/4/36

(C) 2003 Haney et al; licensee BioMed Central Ltd. This is an Open Access article: verbatim copying and redistribution of this article are permitted in all media for any purpose, provided this notice is preserved along with the article's original URL.

\begin{abstract}
Background: Cloning of genes in expression libraries, such as the yeast two-hybrid system (Y2H), is based on the assumption that the loss of target genes is minimal, or at worst, managable. However, the expression of genes or gene fragments that are capable of interacting with $E$. coli or yeast gene products in these systems has been shown to be growth inhibitory, and therefore these clones are underrepresented (or completely lost) in the amplified library.

Results: Analysis of candidate genes as $\mathrm{Y} 2 \mathrm{H}$ fusion constructs has shown that, while stable in $E$. coli and yeast for genetic studies, they are rapidly lost in growth conditions for genomic libraries. This includes the rapid loss of a fragment of the $E$. coli cell division gene fts $Z$ which encodes the binding site for ZipA and FtsA. Expression of this clone causes slower growth in E. coli. This clone is also rapidly lost in yeast, when expressed from a GALI promoter, relative to a vector control, but is stable when the promoter is repressed. We have demonstrated in this report that the construction of libraries for the $E$. coli and $B$. subtilis genomes without passaging through $E$. coli is practical, but the number of transformants is less than for libraries cloned using $E$. coli as a host. Analysis of several clones in the libraries that are strongly growth inhibitory in $E$. coli include genes for many essential cellular processes, such as transcription, translation, cell division, and transport.

Conclusion: Expression of $\mathrm{Y} 2 \mathrm{H}$ clones capable of interacting with $\mathrm{E}$. coli and yeast targets are rapidly lost, causing a loss of complexity. The strategy for preparing $\mathrm{Y} 2 \mathrm{H}$ libraries described here allows the retention of genes that are toxic when inappropriately expressed in $E$. coli, or yeast, including many genes that represent potential antibacterial targets. While these methods are generally applicable to the generation of $\mathrm{Y} 2 \mathrm{H}$ libraries from any source, including mammalian and plant genomes, the potential of functional clones interacting with host proteins to inhibit growth would make this approach most relevant for the study of prokaryotic genomes.
\end{abstract}

\section{Background}

The yeast two-hybrid system is a versatile and powerful system for the identification of proteins that interact directly with a protein target $[1,2]$. This system has had a dramatic effect on studies of eukaryotic processes, such as signal transduction and studies of the cytoskeleton. 
However, the complexity of these libraries presents problems with their handling and amplification. For example, representation of clones that express functional fusions can be lost if the fusion is expressed during amplification, and if is somewhat toxic or growth inhibitory. Many libraries are of eukaryotic origin, and toxicity of library inserts caused by expression of functional domains in $E$. coli, is not typically considered a problem. There are several reasons cited for this. Many of the protein families that are studied in the yeast two-hybrid system are not found in E. coli. This would suggest that expression of fusions within the E. coli host do not have targets that they can interact with. In addition, toxicity of some fusions is a small consequence of the power of the yeast two-hybrid system. Toxicity is a greater problem when considering a two-hybrid system (or other expression library) of prokaryotic origin, since inappropriate expression of an $E$. coli gene is frequently a problem, particularly for genes encoding components of multisubunit complexes and transmembrane proteins.

The problem of toxicity associated with translational fusions to important genes in two-hybrid screening with a prokaryotic library became clear when screens to identify genes that interact with the $E$. coli cell division gene fts $Z$ failed to identify genes that are known to interact with it. These negative results were correlated with the knowledge that $f t s Z$, and many other genes encoding components of the cell division machinery, are unstable when cloned on plasmids, in some cases even when the promoter element is removed. Our decision to develop our own library provided us with the opportunity to look at all the aspects that occur in making a two-hybrid library, and determine how the construction of such a library can best preserve the complexity of a prokaryotic genome.

Thorough screening for genes involved in protein-protein interactions to which E. coli growth is inhibited is a critical component of improving the search for novel antimicrobial compounds. Yet these clones are specifically lost in the construction and amplification of expression libraries. The search for new classes of antimicrobial compounds is a vital part of the long-term management of infectious diseases [3]. Many important new classes of drug targets are proteins that are better represented in these new libraries, including membrane proteins, and protein-protein complexes that $E$. coli carefully regulate, such as those occurring during cell division, transcription and solute transport [4].

\section{Results \\ Stability of fusions which interact with essential gene products in E. coli}

We have examined the steps involved in making a twohybrid library, and tried to identify steps that are particu- larly important for maintaining the complexity of prokaryotic genomic library. As discussed above, the most important step we could identify was to avoid passaging the library through E. coli at any stage. This meant that we would have to transform the ligation products directly into yeast, a step that would make the project much more difficult, since the transformation efficiency of yeast is much lower that that of $E$. coli. If the library was to be used in more than one screen, then an additional element needs to be introduced. The library would have to be transformed into a host strain that does not contain any bait plasmid. The introduction of a bait plasmid for each screen would be done by mating [5]. We chose strain YM4271 because it is a strain that performs well in mating-based two hybrid assays using the Lex system. For this strain, a reporter would also have to be introduced by mating. The fact that the strain lacks both bait and a reporter provides significant flexibility concerning what these plasmids can be, so that improvements in either can be incorporated into later screen designs (see Discussion).

Observations made while working with $f t s Z$ also influenced our decision to develop our library in a pB42-based plasmid. Working with $f t s Z$ in the two-hybrid system suggested that it was somewhat toxic in yeast as well as E. coli. $f t s Z$ hybrids in the Gal system show a reduction in growth rate, and cells appear abnormal when viewed by phase contrast microscopy (results not shown). A significant reduction in growth rate was also observed in the Lex system, when $f t s Z$ was expressed as a fusion to the B42 activation domain, and cells were grown under conditions that induce expression of the fusion. This fusion is under the control of the GAL1 promoter and is not expressed in glucose. Growth in galactose greatly exacerbated the slow growth phenotype, suggesting that the expression of $f t s Z$ is toxic to yeast. We decided it was important to quantitate this effect, especially the extent to which growth in glucose could minimize the loss of growth inhibitory plasmids, preserving complexity of the library.

In this experiment, yeast strain YM4271 was transformed with plasmids $\mathrm{pB} 42$ and $\mathrm{pB} 42-\mathrm{ftsZ}$. These transformants were mated with strain EGY48 that had been transformed with plasmid pLexA. Overnight cultures of the resulting diploids (grown in SD-Trp media) were used to inoculate $100 \mathrm{ml}$ each of YPD and YPGal media. Cultures were grown for 5 hours, at which time aliquots were removed and serially diluted onto YPD plates and SD-Trp plates. Individual colonies were counted and tabulated. The results of one experiment are presented in Table 1. It can be seen in this table that expression of the B42-fts Z fusion through growth in galactose-containing medium is growth inhibitory to yeast. The effect was not as dramatic when the Gal4AD-ftsZ fusion was compared a vector control when grown in YPD for several generations (results 
Table I: Plasmid Loss During Growth in Rich Media

\begin{tabular}{|c|c|c|c|c|}
\hline Plasmid & Media & Plate & Colonies & Percent lost \\
\hline \multirow[t]{4}{*}{ pB42 } & YPD & YPD & 112 & 13 \\
\hline & & SD-Trp & 97 & \\
\hline & YPGal & YPD & 127 & 13 \\
\hline & & SD-Trp & 110 & \\
\hline \multirow[t]{4}{*}{ pB42-ftsZ } & YPD & YPD & 126 & 8 \\
\hline & & SD-Trp & 116 & \\
\hline & YPGal & YPD & 98 & 92 \\
\hline & & SD-Trp & 8 & \\
\hline
\end{tabular}

Yeast strain YM427I transformed with the plamids indicated in the table were grown for 5 hours in YPD or YPGal (as indicated) and plated as serial dilutions on both YPD and SD-Trp. Colonies growing from these cultures following $100 \mu \mathrm{l}$ of a I:10000 dilution were counted. Data from this experiment is representative of four separate experiments.

not shown). However, even subtle differences in the growth rate of functional clones, through the constitutive expression of plasmids in the Gal system, would be an additional liability for maximum complexity of the library. Thus, we felt that a library cloned behind the GAL1 promoter, and expressed in glucose offered the best way to limit the loss of plasmids that express important fusions.

\section{Construction of E. coli and B. subtilis $\mathrm{Y2H}$ libraries directly in yeast}

We decided to base our strategy for the cloning portion of this project on the strategy developed by James et al [6]. In that report, they modified the multiple cloning site of pGAD424 to allow the ligation of insert digested with a family of restriction enzymes that cleave DNA at various four-base recognition sequences such that they produce two-base overhangs that can be cloned into a ClaI restriction site. We developed polylinkers that included a ClaI site, as well as other restriction sites such as EcoRI and BglII. These last two restriction sites allow the cloning of DNA that has been digested with Tsp501I and Sau3A, respectively. These last two enzymes were included because of the increased efficiency of ligation of restriction fragments with a four-base pair overhang, compared with the two-base pair overhang. The increased efficiency of ligation was seen as a factor to compensate for the lower efficiency of transformation into yeast, relative to $E$. coli. The multiple cloning site cassette was constructed in all three reading frames. DNA from the $E$. coli strain MG1655 and the B. subtilis strain 168 were chosen for this library because they well characterized genetically, and have been completely sequenced. Chromosomal DNA was isolated and prepared for cloning by partial digestion with several enzymes as listed in Table 2.

DNA ligations were transformed directly into YM4271. To do this as effectively as possible, the strain was carefully characterized to determine the conditions in which it had the highest transformation efficiency. Yeast strains are readily transformable by both electroporation and with lithium acetate $[7,8]$. However, the conditions in which they do this with maximum efficiency is strain dependent. Using the lithium acetate transformation procedure as an example, some strains transform well after a 15 minute heat shock, whereas other do not transform well with less than a 30 minute heat shock $[7,9]$. Purified partial digests were mixed with digested, phosphatased vector DNA in titration experiments and scored by transformation in $E$ coli, solely as a means of determining the number of successful ligations. The amount of vector DNA and the ratio of insert to vector DNA were examined. Optimal conditions determined in the test reactions were repeated in multiple ligations for each sample of insert DNA. Ligation reactions were transformed into yeast made competent by treatment with lithium acetate. Transformation reactions were pooled by insert preparation, but not vector reading frame, and used to inoculate $500 \mathrm{ml}$ of -Trp media. Cultures were grown to an OD of 0.8 to 1.2 , pelleted and resuspended in $50 \mathrm{ml}$ medium for freezing. Aliquots were taken after transformation to determine the total number of transformants, and after freezing, to determine the titer. The results are presented in Table 2. Table 2 lists the restriction enzymes used to generate the fragments, along with their cut site frequencies and number of fragments generated for a complete digestion (or total 5 ' ends). The table also includes an estimation of the extent to which all potential clones have been generated, as described by Finkel et al. [10], discussed further in the next section.

\section{Analysis of library clones}

We analyzed the clones of the library in three ways. The first is the fraction of clones that contain inserts. The second is a statistical analysis of the predicted coverage of the genomes, based on the number of clones obtained in each of the pools and the number of restriction sites in the 
Table 2: Analysis of Yeast Two-Hybrid Libraries to the E. coli and B. subtilis genomes.

\begin{tabular}{|c|c|c|c|c|c|c|c|c|c|}
\hline Pool & Vector Digest & Insert digest & Site frequency (\%) & $\begin{array}{l}\text { Predicted number } \\
\text { of } 5 \text { ' ends }\end{array}$ & Transformants & $\begin{array}{l}\text { Transformants } \\
\text { /vector }\end{array}$ & $\mathrm{FI}$ & $\begin{array}{l}\text { Expected number } \\
\text { of } 5^{\prime} \text { ends missing }\end{array}$ & $\begin{array}{l}\% \text { coverage I } \\
\text { pool }\end{array}$ \\
\hline EI & EcoRI & Tsp509I & 0.306 & 35728 & $1,560,000$ & 520,000 & $4.78 \mathrm{E}-07$ & 0 & 100 \\
\hline E2 & Clal & Mspl & 0.511 & 55200 & 240,000 & 80,000 & 0.238 & 12957 & 77 \\
\hline E3 & Clal & Maell & 0.403 & 30360 & 230,000 & 76,667 & 0.088 & 2430 & 92 \\
\hline E4 & Clal & Taq $\alpha 1$ & 0.325 & 35728 & 230,000 & 76,667 & 0.117 & 4179 & 88 \\
\hline E5 & BgIII & Sau $3 A$ & 0.416 & 35728 & $1,310,000$ & 436,667 & $4.92 \mathrm{E}-06$ & 0 & 100 \\
\hline BI & EcoRI & Tsp509I & 0.655 & 55232 & 998,000 & 332,667 & 0.00242 & 134 & 100 \\
\hline B2 & Clal & Mspl & 0.38 & 32034 & 165,000 & 55,000 & 0.180 & 5754 & 82 \\
\hline B3 & Clal & Maell & 0.237 & 19986 & 260,000 & 86,667 & 0.013 & 261 & 99 \\
\hline B4 & Clal & Taq $\alpha 1$ & 0.286 & 24028 & 222,000 & 74,000 & 0.0460 & 1105 & 95 \\
\hline B5 & BgIII & Sau3A & 0.472 & 39762 & $1,320,000$ & 440,000 & $1.56 \mathrm{E}-05$ & 1 & 100 \\
\hline
\end{tabular}

Calculations of site frequencies and prediction of the number of 5 ' ends are based on published genome sequences.

genome for the restriction enzymes used to prepare the insert DNA. The third is the identification and analysis of inserts that are stable in yeast, but not in E. coli. Transformants from the yeast library pools were isolated as single colonies and their plasmids isolated. These plasmid samples were then transformed into E. coli. For the colonies recovered by transformation into $E$. coli strain DH10B in each of the pools, a majority of the plasmids characterized by restriction digest showed inserts.

The second analysis of these libraries was a statistical review of theoretical representation of inserts captured by the library pools. This analysis is a comparison of the number of clones generated with the number of clones theoretically possible, based on the number of restriction sites for the enzymes used to prepare the genomic DNA in the genome. The result is a measure of the likelihood that a specific insert is represented as a clone in a library pool, and is usually expressed as the "Expected Number of 5' Ends Missing". This analysis shows the principal liability associated with cloning the ligation products directly in yeast, when compared to libraries prepared by cloning into $E$. coli $[6,11,12]$. In these projects, the efficiency of $E$. coli as a host allows complete coverage of the potential pools, based on the number of transformants. In the libraries described here, several pools are missing a fraction of the expected number of potential fusion junctions.

Lastly, we examined the rationale that cloning directly in yeast allows inclusion of unstable clones, particularly those that encode fusions that are growth inhibitory because of inappropriate expression in $E$. coli. In order to characterize the stability of the plasmids in E. coli, diploids of the library-containing yeast strain YM4271 were mated with EGY48 that contained the pLexA vector and the plex(OP)8-lacZ reporter construct. From these diploids, plasmids were recovered and transformed into $E$. coli strain KC8, which allows the specific rescue of bait plasmids through the complementation of the $\operatorname{trp} B$ mutation by the TRP1 gene. Following transformation, transformants were spotted onto (A) plates that allowed for the selection of any of the plasmids (vector, reporter or library), because each plasmid confers ampicillin resistance, or (B) onto plates that specifically selected for the library plasmid because only it will complement the $\operatorname{trp} B$ mutation of the host. The results are seen in Figure 2. In part $\mathrm{A}$, all the tranformants grew as spots, whereas in part $\mathrm{B}$, several of the transformants did not grow. In particular, some of the spots showed some meager growth after 16 hours at $37^{\circ} \mathrm{C}$, and others did not grow at all (cf. the first, second and fourth spots in the second row). For those transformants that were growth retarded, we analyzed the insert of the pB42 fusion to see if the strain carried a hybrid that could account for the aberrant growth. Several plasmid inserts were amplified by PCR and sequenced. The inserts were in-frame fusions of the $\mathrm{B} 42$ activation domain to the genomic sequences listed in Table 3. Genes for several essential processes were identified, including transcription and translation, and solute transport. While difficulties in working with membrane proteins such as transporters, in the two-hybrid system have been noted before $[11,13]$, cloning of integral membrane proteins using the $\mathrm{Y} 2 \mathrm{H}$ system have been reported [14]. Other systems exist for studying protein-protein interactions involving membrane proteins, as well [15]. We do not foresee this system completely replacing such systems, but if protein under study does interact with a membrane protein, previous experience indicates that it can be identified in the Y2H system if it is present in the library. The data reported here supports the suggestions that many fusions may be lost or underrepresented in a two-hybrid library due to growth defects caused by inappropriate expression in E. coli. 


\section{AATTT(gீ)CATATGCCATGGGAATTCATCGATCCCGGGAGATCTC}

$$
\text { Nde I Nco I Eco RI Cla I Sma I Bgl II }
$$

\section{Figure I}

Sequence of the polylinker. The polylinker for pB42-CI is shown. Restriction sites are underlined and labeled. The sequence of $\mathrm{pB} 42-\mathrm{C} 2$ and $\mathrm{pB} 42-\mathrm{C} 3$ are identical except for the addition of one and two additional $\mathrm{G}$ residues immediately prior to the EcoRl site, as indicated.

Table 3: Fusions to B42 that are unstable in E. coli

\begin{tabular}{|c|c|c|}
\hline Library & Insert & Comments \\
\hline \multirow[t]{7}{*}{ E. coli } & YdaW & putative membrane protein \\
\hline & YaaU & probable transporter \\
\hline & PhoQ & transmembrane receptor \\
\hline & YjcE & putative $\mathrm{Na}^{+} / \mathrm{H}^{+}$antiporter \\
\hline & GalR & gal operon repressor protein \\
\hline & YicE & hypothetical xanthine/uracil permease \\
\hline & $\operatorname{PrfC}$ & polypeptide release factor 3 \\
\hline \multirow[t]{8}{*}{ B. subtilis } & YwtA & polyglutamate biosynthesis \\
\hline & Yval & EcSecG homolog, peptide secretion \\
\hline & MreB & Bacterial actin homolog, cell shape determination \\
\hline & Ywd & Ipa-60d, homology to purine permeases \\
\hline & $\operatorname{TrpB}$ & Tryptophan synthase, beta subunit \\
\hline & Cots & Spore coat protein \\
\hline & Mfd & Removes RNA pol from DNA lesions \\
\hline & YrvE & Homology to ssDNA exonuclease \\
\hline
\end{tabular}

\section{Design of the library screen}

The library can be screened with a mating strategy. The library in strain YM4271 is revived and mixed with an excess of strain EGY48 that contains the bait plasmid (pLexA) and the reporter constructs (the high copy plasmid plex(OP)8-lacZ and the chromosomal lex(OP)6LEU2 fusions). The strains are incubated in YEPD for 2-4 hours to allow zygotes to form, but before significant growth resumes. Diploids that carry presumptive interacting proteins would be selected on LUTH/GalRaf plates. These could then be screened directly by replica printing to LUTH/Xgal/GalRaf plates. Plasmid DNA from the colonies would then be prepared to recover the prey plasmids from strains that score positive. Prey plasmids that can be recovered as stable transformants in $E$. coli may be retested by retransforming into yeast and rechecking the $\mathrm{Leu}^{+}$and $\mathrm{X}-\mathrm{Gal}{ }^{+}$phenotypes, along with controls that would show whether these phenotypes are specific for the bait interaction. Plasmids that cannot be recovered in E. coli can be analyzed by PCR and sequence analysis of the insert. The sequence of the insert can then be used to determine if the clone represents a potentially interesting interaction. These can then be followed up by one of several methods, including cloning the insert under a stongly repressed promoter, such as $a r a B$, or altering growth conditions to favor the growth of the clone in E. coli. For example, inappropriate expression of many of the genes required for cell division show reduced toxicity when coexpressed with $\mathrm{pZAQ}$, a plasmid that expresses fts $Z, f t s A$ and $f t s Q$ in amounts and proportions that allow cell division to continue [16-18].

\section{Discussion}

The strategy described in this work seeks to address several reasons that can limit the complexity of genomic libraries, particularly two-hybrid libraries. Two-hybrid libraries, and some other expression libraries, have unusually high requirements for the number of clones needed for complete representation of a genome. The one change that affects this strategy the most is that the ligation products are transformed directly into yeast, rather than the more usual E. coli host. The advantage of the method described here is that it directly addresses the potential of clones to 
be lost from the library during the amplification and passaging stages. Toxicity as a consequence of expression in yeast can also be limited by maintaining the library in a transcriptionally dormant state through growth in glucose. Gene fragments that are toxic when expressed in $E$. coli are particularly troubling in a search for antibacterial targets, because they represent exactly the genes of greatest interest as potential targets: genes whose expression is tightly controlled because they impinge on very sensitive processes. The challenge of developing the library in yeast is the significantly lower transformation efficiency of yeast as compared to E. coli. However, this method will still have a role in developing a complete genomic analysis when there is reason to think that toxicity is a problem, such as circumstances described in this report. The use of libraries that retain complexity of growth inhibitory fusions should aid in both biological studies and in the search for novel therapeutic strategies, which are key to meeting the challenge of resistance to currently available antibiotics $[3,4]$.

\section{Conclusions}

The method described in this report will allow genes that affect essential functions in E. coli to be cloned much more readily than current versions of the $\mathrm{Y} 2 \mathrm{H}$ system, because the growth-inhibitory consequences of these interactions during construction of the library are bypassed.

\section{Methods}

\section{Media, reagents and strains}

Yeast strains EGY48, YM4271, bacterial strain KC8, and plasmids pLexA, plex(OP)8-lacZ and pB42, were obtained from BD/Clontech (Palo Alto, CA), and were described previously [19]. E. coli strain DM1 is from Invitrogen (Carlsbad, CA). Media is from Difco and Bio101, and is prepared according to standard recipes [20,21]. Restriction enzymes, T4 DNA ligase and related enzymes were purchased from New England Biolabs (NEB, Beverly, MA), Boehringer Mannheim Biochemicals (BMB, Indianapolis, IN) or Invitrogen. Plasmids used to test the $\mathrm{Y} 2 \mathrm{H}$ system were constructed from vectors obtained from $\mathrm{BD} /$ Clontech, as described elsewhere [Haney, S., L. Chen, and S.J. Projan, manuscript in preparation 2003]. Other reagents were from standard suppliers.

\section{Preparation of chromosomal DNA}

A $100 \mathrm{ml}$ culture of $E$. coli strain MG1655, grown in 2xYT, was pelleted and washed with $50 \mathrm{ml}$ of TES buffer $(50 \mathrm{mM}$ Tris- $\mathrm{HCl}, \mathrm{pH} 8.0 ; 5 \mathrm{mM}$ EDTA; and $50 \mathrm{mM} \mathrm{NaCl}$ ). The cells were pelleted again and resuspended in $24 \mathrm{ml}$ of $25 \%$ sucrose and $50 \mathrm{mM}$ Tris $\mathrm{pH} 8.0$, and incubated on ice for $20 \mathrm{~min} .12 \mathrm{ml}$ of a solution containing $10 \mathrm{mg} / \mathrm{ml}$ lysozyme and $0.25 \mathrm{mM}$ EDTA, pH 8.0 was added, and the solution was mixed by inversion several times. $7.5 \mathrm{ml}$ of lysis solution (5\% sarkosyl, $50 \mathrm{mM}$ Tris $\mathrm{pH} 8.0$, and 62.5 mM EDTA) was added and the sample was mixed by inversion. $5 \mathrm{ml}$ of a $10 \mathrm{mg} / \mathrm{ml}$ solution of proteinase $\mathrm{K}$ (BMB) was added and the sample was mixed by inversion and incubated at $55^{\circ} \mathrm{C}$ for $60 \mathrm{~min}$. The sample was extracted with an equal volume of TE saturated phenol and again with PCI (TE saturated phenol, chloroform, isoamyl alcohol, 25:24:1). Two to three milligrams of DNA are typically recovered.

$100 \mathrm{ml}$ of $B$. subtilis strain 160 was grown to saturation in BHT media (Difco Labs, Detroit, MI) for 16 hours. The cells were washed once in $50 \mathrm{ml}$ EET (100 mM EDTA, 10 $\mathrm{mM}$ EGTA and $10 \mathrm{mM}$ Tris, $\mathrm{pH}$ 8.0). The cells were then resuspended in $15 \mathrm{ml}$ EET. $1.5 \mathrm{ml}$ of a $10 \mathrm{mg} / \mathrm{ml}$ solution of lysozyme and $0.5 \mathrm{ml}$ of a $10 \mathrm{mg} / \mathrm{ml}$ solution of RNase A were added. The solution was incubated for $30 \mathrm{~min}$ at $37^{\circ} \mathrm{C}$. An additional $4.5 \mathrm{ml}$ of EET (100 mM EDTA, 10 mM EGTA, 10 mM Tris, pH 8.0) was added along with 1.5 $\mathrm{ml}$ of $20 \%$ SDS and $1 \mathrm{ml}$ of a $10 \mathrm{mg} / \mathrm{ml}$ solution of proteinase $\mathrm{K}$. The solution was incubated for $10 \mathrm{~min}$ at $65^{\circ} \mathrm{C}$. $1 \mathrm{ml}$ of $5 \mathrm{M} \mathrm{NaCl}$ was added, the solution mixed thoroughly. $0.8 \mathrm{ml}$ of a $10 \% \mathrm{CTAB} / 0.7 \mathrm{M} \mathrm{NaCl}$ solution was added, and the solution mixed thoroughly again. The solution was extracted with $20 \mathrm{ml}$ of PCI (25:24:1 Phenol:Chloroform:Isoamyl Alcohol), and the aqueous phase transferred to new tube. $4.5 \mathrm{ml}$ of isopropanol was added and the solution was incubated for $15 \mathrm{~min}$ at RT, followed by centrifugation at $15 \mathrm{~K} \mathrm{rpm}$ for $20 \mathrm{~min}$. The pellet was washed with $70 \%$ ethanol, recentrifuged and resuspended in $1 \mathrm{ml}$ of TE (10 mM Tris, $1 \mathrm{mM}$ EDTA, pH8.0.).

\section{Construction of modified pB42 vectors, and preparation for ligation to insert DNA}

Plasmid pB42 was digested with XhoI and EcoRI to completion, and precipitated and digested with CIP (NEB). This vector was then split into three reactions, where three pairs of oligos were added to form the new multiple cloning sites. The annealed and ligated oligonucleotides result in the multiple cloning site sequences depicted in Figure 1. After annealing, the reactions were incubated with T4 DNA ligase overnight, and transformed into E. coli. For plasmids to be digested with ClaI, the three plasmids were transformed into E. coli strain DM1, and transformants were prepared using the Qiagen Plasmid Maxiprep kit (Valencia, CA), according to the manufacturers instructions. For each set of transformation reactions, plasmid DNA was prepared as follows: $100 \mu \mathrm{g}$ of DNA was digested with EcoRI, ClaI or BglII to completion. DNA was precipitated with ethanol and ammomium acetate according to standard protocols, and resuspended in $50 \mu \mathrm{l}$ of water, buffer and shrimp alkaline phosphatase, as described by the manufacturer (BMB). The sample was heat inactivated, and the DNA was purified by TAE gel 


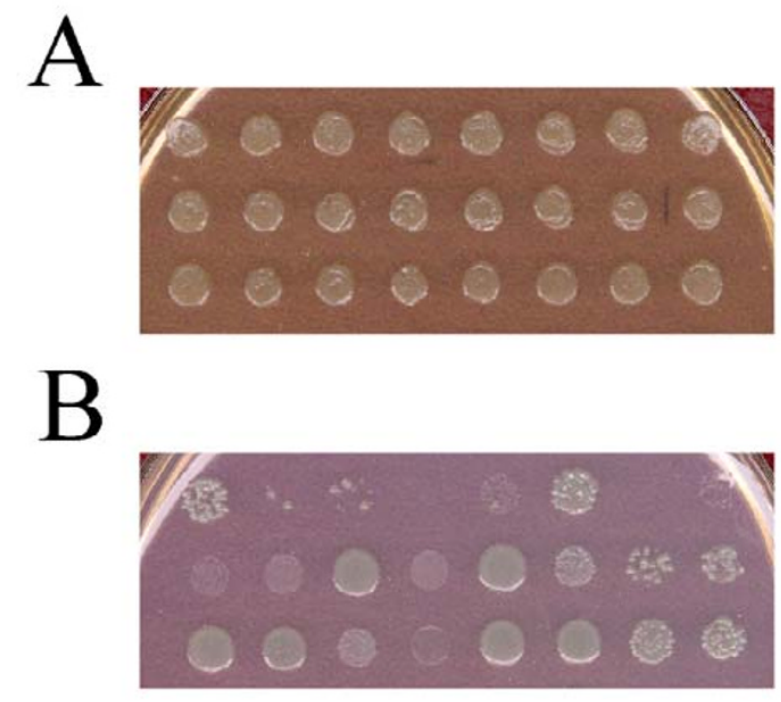

\section{Figure 2}

Characterization of clones from the yeast two-hybrid library. Plasmids recovered from yeast strain YM427I were transformed into $E$. coli strain $\mathrm{KC} 8$ by electroporation. Tranformants were selected by spotting the transformation mixture onto M9 plates supplemented with tryptophan (A) or M9 plates that were not supplemented with tryptophan (B).

electophoresis, and Qiagen QiaQuick clean-up prep. 100 ng of DNA was transformed into yeast strain YM4271, as described below, to assure that very little ccDNA remained, as measured by the number of colonies resulting from such a transformation. The number of transformants under such a test ranged from 0-60, whereas $100 \mathrm{ng}$ of ccDNA typically gives $10^{4}$ colonies, or greater, under similar transformation conditions.

\section{Preparation of genomic inserts}

Chromosomal DNA from strain MG1655 was digested with a sufficient amount of the indicated restriction enzyme to completely digest the DNA in 1 hour (typically 1-5 units of enzyme/ $\mu$ g of DNA). Partial digestion was achieved by withdrawing samples of the reaction at various time points and stopping the reaction by adding the sample to an equal volume of $20 \mathrm{mM}$ EDTA on ice. The enzymes were: Tsp509I (NEB), which was to be cloned into the EcoRI sites of the vectors, MaeII (BMB), MspI (NEB), and Taq ${ }^{\alpha} I$ (NEB), which were all to be cloned into the ClaI sites, and Sau3A (NEB), which was to be cloned into the BglII site. Optimal partial digestion of the DNA was determined as the length of time needed for the majority of the sample to consist of fragments that ranged from $500 \mathrm{bp}$ to $4 \mathrm{~kb}$. These conditions, including an opti- mal digestion time that was typically 2-5 minutes, were then used to digest a larger sample of chromosomal DNA under identical conditions, and the samples were isolated by TAE/agarose gel electrophoresis. Samples in the size range of $500 \mathrm{bp}$ to $2 \mathrm{kbp}$ were purified by extraction with phenol.

\section{Ligation and transformation in yeast}

Ligation reactions for each set of partially digested inserts were performed in two parts. In the first, the optimal vector/insert ratio was determined empirically. $100 \mathrm{ng}$ of vector was incubated with increasing amounts of insert DNA (typically from $50 \mathrm{ng}$ to $500 \mathrm{ng}$ ) in a ligation reaction of constant volume $(50 \mu \mathrm{l})$ overnight at $16^{\circ} \mathrm{C}$, using T4 DNA ligase (NEB). Samples for each condition were transformed into E. coli strain DH10B (Invitrogen) by electroporation, and the number of colonies was scored as a measure of the optimal ratio for the ligation. When this ratio was determined, new ligation reactions were set up (four reactions, $500 \mu \mathrm{l}$ each) and used for the transformation in yeast. The second part was the transformation of the ligation into yeast. The maximal transformation efficiency of yeast strain YM4271 was determined systematically. For this strain, maximal efficiency was achieved after preparation of the competent cells that had been grown to an OD 0.8 , incubation in $0.1 \mathrm{M}$ lithium acetate overnight at $4{ }^{\circ} \mathrm{C}$, and heat shock at $42^{\circ} \mathrm{C}$ for 30 minutes in a transformation mixture that contains $10 \%$ DMSO. For the transformation of the ligation products into yeast, 40 transformation tubes were set up, where $50 \mu$ l of cells were incubated with $50 \mu \mathrm{l}$ of the ligation mixture in the transformation mixture. Following heat shock, the cells were centrifuged at $5 \mathrm{~K} \mathrm{rpm}$ in a microfuge for 3 minutes, and the cells were gently resuspended in $100 \mu \mathrm{l}$ of YPD and allowed to sit at RT for two hours. The cells were then pooled and added to $500 \mathrm{ml}$ of SD-Trp and $100 \mu \mathrm{l}$ removed for titering. The remaining culture was grown with moderate agitation for 16 hrs. The cultures were then chilled, pelleted and resuspended in $50 \mathrm{mls}$ of $15 \%$ glycerol and frozen at $-70^{\circ} \mathrm{C}$. The samples removed for titering were serially diluted and plated onto -Trp plates for determination of the total number of transformants. A sample of the frozen stock was also titered.

\section{Characterization of the library}

Identification of inserts toxic to $E$. coli were characterized as follows. Samples from the amplified library pools were streaked onto SD-Trp plates and grown as single colonies. Colonies were grown as $5 \mathrm{ml}$ overnight cultures and the plasmids isolated as described. Plasmids were analyzed by transfomation into the bacterial strain KC8 (BD/Clontech) by electroporation, as described, and amplified by PCR using Taq polymerase and oligos that flank the MCS (5'-CTCTGGCGAAGAAGTCCAAAGCTTCTCG, 5'CAGCCTGACTGGCTGAAATCGAATGGTTTTC). The 
products were sequenced and the genomic inserts identified by BLAST [22].

\section{Authors' Contributions}

SH performed the experiments in Figure 1, prepared the chromosomal DNA, and constructed the libraries. DK constructed the cloning vectors. LC tested the libraries in Y2H screens and analyzed clones recovered. SM prepared chromosomal DNA and provided general technical assistance. SP provided guidance and support. BR designed the cloning vectors and provided guidance.

\section{Abbreviations}

$\mathrm{Y} 2 \mathrm{H}$, yeast two-hybrid; PCI, phenol-chloroform-isopropanol (25:24:1); YPD, yeast-peptone media with dextrose (2\%); SD, synthetic defined media with complete supplements except as indicated; CIP, calf intestinal phosphatase.

\section{Acknowledgements}

We would like to thank Kim Arndt, for technical suggestions during the course of this project, and Piet de Boer, who discussed the difficulties of cloning components of the septal complex by $\mathrm{Y} 2 \mathrm{H}$, and the role of inappropriate expression may play in maintaining complexity.

\section{References}

I. Gyuris JE, Golemis E, Chertkov H and Brent R: Cdil, a human Gland $S$ phase protein phosphatase that associates with Cdk2. Cell 1993, 75:791-803.

2. Fields $S$ and Song O: A novel genetic system to detect proteinproteini interactions. Nature 1989, 340:245-246.

3. Haney S, Alksne LE, Dunman PM, Murphy E and Projan SJ: Genomics in Anti-Infective Drug Discovery-Getting to Endgame. Current Pharmaceutical Design 2002, 8:1099-1II8.

4. Hogan $D$ and Kolter R: Why are bacteria refractory to antimicrobials? Current Opinion in Microbiology 2002, 5:472-477.

5. Bendixen C, Gangloff $S$ and Rothstein R: A yeast mating-selection scheme for detection of protein-protein interactions. Nucleic Acids Research 1994, 22:1778-1779.

6. James P, Halladay J and Craig EA,: Genomic libraries and a host strain designed for highly efficient two-hybrid selection in yeast. Genetics 2003, I 44: I 425 - I 436.

7. Schiestl RH and Gietz RD: High efficiency transformation of intact yeast cells using single stranded nucleic acids as a carrier. Current Genetics 1989, 16:339-346.

8. Becker DM and Guarente L: High efficiency transformation of yeast by electroporation. Guide to Yeast Genetics and Molecular Biology Volume 194. Edited by: Gutherie C and Fink GR. San Diego, Academic Press; 1991:182-187.

9. Gietz RD, Schiestl RH, Willems AR and Woods RA: Studies on the transformation of intact yeast cells by the LiAc/SS-DNA/ PEG procedure. Yeast Apr 15; 1995, I I:355-360.

10. Finkel RA, Bent $S$ and Schardl CL: Determining the probability of obtaining a desired clone in an amplified or shuttle library. BioTechniques 1994, 16:580-582.

II. Johnsson $\mathrm{N}$ and Varshavsky A: Split ubiquitin as a sensor of protein interactions in vivo. Proc.Natl. Acad.Sci. USA 1994, 91:10340-10344.

12. Kabani M, Boisrame A, Beckerich J-M and Caillardin C: A highly representative two-hybrid genomic library for the yeast Yarrowia lipolytica. Gene 2000, 241 :309-315.

13. Brachmann RK and Boeke JD: Tag games in yeast: the two hybrid system and beyond. Current Opinion in Biotechnology 1997, 8:56I-568

14. Xue Y, Batlle M and Hirsch JP: GPRI encodes a putative G protein-coupled receptor that associates with the Gpa2p Gal- pha subunit and functions in a Ras-independent pathway. EMBO J. 1998, 17:1996-2007.

15. Aronheim A, Zandi E, Hanneman H, Elledge SJ and Karin M: Isolation of an AP-I repressor by a novel method for detecting protein-protein interactions. Molecular and Cellular Biology 1997, 17:3094-3102.

16. Dai K, Mukherjee $A, X u Y$ and Lutkenhaus J: Mutations in ftsZ that confer resistance to SulA affect the interaction of FtsZ with GTP. Journal of Bacteriology 1994, 175: I30-136.

17. de Boer PA, Crossley RE and Rothfield LI: Central role for the Escherichia coli minC gene product in two different cell division-inhibition systems. Proc. Natl. Acad. Sci. USA 1990, 87: II29-II33.

18. Hale CA and de Boer PAJ: ZipA is required for recuitment of FtsK, FtsQ, FtsL and FtsN to the septal ring in Escherichia coli. J. Bacteriology 2002, 184:2552-2556.

19. Golemis EA and Brent R: Searching for interacting proteins with the two-hybrid system III. The Yeast Two-Hybrid System Edited by: Bartel PA and Fields S. Oxford, UK, Oxford University Press; 1997.

20. Gutherie $C$ and Fink GR: Guide to Yeast Genetics and Molecular Biology. Methods in Enzymology Volume 194. San Diego, Academic Press; 1991.

21. Adams A, Gottschling DE, Kaiser CA and Stearns T: Methods in Yeast Genetics. Cold Spring Harbor, Cold Spring Harbor Press; 1997.

22. Haney $S$, Chen $L$ and Projan SJ: The cell division inhibitor Kilracl OrfE binds directly to ZipA. BMC Molecular Biology (submitted) 2003.

23. Altschul SF, Madden TL, Schäffer AA, Zhang J, Zhang Z, Miller W and Lipman DJ: Gapped BLAST and PSI-BLAST: a new generation of protein database search programs. Nucleic Acids Res. 1997, 25:3389-3402.
Publish with Bio Med Central and every scientist can read your work free of charge

"BioMed Central will be the most significant development for disseminating the results of biomedical research in our lifetime. "

Sir Paul Nurse, Cancer Research UK

Your research papers will be:

- available free of charge to the entire biomedical community

- peer reviewed and published immediately upon acceptance

- cited in PubMed and archived on PubMed Central

- yours - you keep the copyright 